\title{
Poesías completas
}

\section{Cristobal Mosquera de Figueroa}

ed. de Jorge León Gustà, Sevilla, Alfar, 2015, 424 pp.

Cristóbal Mosquera de Figueroa es el escritor contemporáneo citado con mayor profusión en las Anotaciones de Fernando de Herrera a la obra poética de Garcilaso y, sin embargo, carecíamos hasta la fecha de edición íntegra y crítica de sus versos. No puede, en efecto, dársele este nombre a la de Guillermo Díaz Plaja (Poesías inéditas, Madrid, R.A.E., 1955), puesto que estaba basada exclusivamente en uno, el mejor, de los manuscritos disponibles.

Discípulo de Juan de Mal Lara y del propio Fernando de Herrera, parece que Cristóbal Mosquera de Figueroa fue asiduo de la tertulia de los condes de Gelves, donde pudo conocer a ingenios tales como Luis Barahona de Soto, Juan de la Cueva, Baltasar del Alcázar o Cristóbal de Mesa. Sabemos además que mantuvo cordiales relaciones de amistad con Cervantes y Alonso de Ercilla. A diferencia de la mayoría de sus pares andaluces, optó por el cauce manuscrito para la difusión de sus versos. En concreto, y dejan- do de lado las composiciones contenidas en preliminares de terceros, las obras de Cristóbal Mosquera de Figueroa se nos han conservado, básicamente, en dos manuscritos: el ms. 2051 de la Biblioteca de Cataluña y el ms. R-49481 de la Biblioteca del Castillo de Peralada, en Gerona. Según Jorge León Gustà, el segundo de los manuscritos es copia del primero, con lo que sus aportaciones textuales carecen de relevancia. Contiene, sin embargo, algunas composiciones $y$ fragmentos ausentes en el ms. de la Biblioteca de Cataluña y que Guillermo Díaz Plaja, el primer editor moderno de Mosquera, no pudo tener en cuenta. El primero de los manuscritos, a su vez, es un apógrafo $-y$ no un autógrafo, según se creía- que, muy probablemente, fue revisado y corregido por un relativamente anciano Cristóbal Mosquera de Figueroa.

Jorge León Gustá elige editar siguiendo el orden del ms. 2051 de la Biblioteca de Catalunya, que, curiosamente, no se atiene a crite- 
rios métricos ni exactamente temáticos. En él, según era costumbre, aparecen en primer lugar las composiciones sacras y, a continuación, las profanas; entre estas, los metros italianos preceden a los castellanos. Lo curioso es que la disposición de los metros italianos no sigue, según decía, criterios métricos ni, en rigor, temáticos, sino que obedece a la contraposición entre composiciones con destino público (odas y elegías funerales, por ejemplo) y composiciones con destino privado (elegías amorosas, por caso). Entre ambos bloques existe una serie de sonetos que sirven de bisagra o eje de la colección. En su introducción, no obstante, Jorge León Gustà elige el criterio genérico a la hora de realizar el análisis pormenorizado de la colección, que lleva a cabo con un aprovechamiento generoso de los volúmenes del grupo P.A.S.O. en torno a la cuestión (La silva, 1991; La oda, 1993; La elegía, 1996; etc.). Debido quizás a la propia historia de la edición, que tiene su origen en una tesis doctoral leída en 2002, las referencias se encuentran ligeramente obsoletas y se echa en falta alguna actualización.

La poesía religiosa de Cristóbal Mosquera de Figueroa gira en torno a las diferentes circunstancias e instrumentos de la Pasión, con alguna pequeña excepción. Es interesante, en efecto, su «Prólogo [...] a la famosa tragicomedia de Santa Catarina», con algunas observaciones sobre teoría dramática. En cuanto a su poesía italianizante, enunciaría el principio organizador de la colección de forma ligeramente distinta a como lo hace Jorge León Gustà. En mi opinión, las dos partes del conjunto no se disponen exactamente de acuerdo con el eje "composiciones públicas vs. composiciones privadas", sino más bien en función de la contraposición entre composiciones circunstanciales y composiciones no circunstanciales, lo que, en verdad, no es sino utilizar palabras distintas para sostener lo mismo que Jorge León Gustà. Las primeras piezas de la colección son, efectivamente, de carácter circunstancial y aparecieron, en muchos casos, entre los paratextos de obras de terceros. Es interesante señalar, desde el punto de vista de las redes de sociabilidad contemporáneas, que Cristóbal Mosquera de Figueroa y Fernando de Herrera comparten espacio preliminar en varias obras del momento. Ambos contribuyen, por ejemplo, a la Descripción de la galera real del serenísimo señor don Juan de Austria, de Juan de Mal Lara, 
y a la Filosofía de las armas y de su destreza y de la agresión y defensión cristiana, de Jerónimo Carranza. Se intercambian entre sí, además, dos sonetos: «Cese, que es tiempo ya, el lamento mío» (Herrera) y «Si no entendiese que un doliente pecho» (Mosquera de Figueroa). La más conocida de las composiciones de Cristóbal Mosquera de Figueroa es, posiblemente, su «Elegía a Garcilaso de la Vega, en su muerte», presente en los preliminares de las anotaciones de Fernando de Herrera y de la que la tradición manuscrita proporciona, sin embargo, variantes que apuntan a una reescritura posterior a 1580 .

Ya se ha indicado que Cristóbal Mosquera de Figueroa es el autor aurisecular citado con mayor frecuencia en las glosas de Fernando de Herrera a las obras en verso de Garcilaso. Sucede que gran parte de las traducciones de Mosquera conservadas en dichas glosas o anotaciones han llegado hasta nosotros, exclusivamente, gracias a la propia edición de Herrera, de donde se deduce que fueron compuestas a petición del Divino, con el solo objeto de ilustrar determinadas aseveraciones de su discurso crítico. Las virtudes de Cristobal Mosquera de Figueroa como traductor se aprecian, con todo, en al- gunas de las piezas conservadas por vía manuscrita, como su paráfrasis del epigrama "Vitam quae faciant beatiorem» de Marcial (véanse las págs. 227-229) o su versión de la oda «Quis multa gracilis te puer in rosa» de Horacio (véanse las págs. 352-353), piezas ambas con fecunda descendencia en las diversas literaturas europeas.

El corpus de la poesía de Cristóbal Mosquera y Figueroa, tal y como podemos apreciar ahora gracias a la edición íntegra de Jorge León Gustà, no basta para sacarle del purgatorio de los autores menores. Si le recordamos a día de hoy es en virtud, más que de sus contribuciones propias, de sus vínculos con otros personajes de la escena literaria, como, por traer a colación algún nombre distinto de los ofrecidos más arriba, Francisco de Salinas, el protagonista de la oda tercera de fray Luis, a quien Cristóbal Mosquera de Figueroa, que le conocía de sus tiempos de estudiante salmantino y era, por lo visto, intérprete notable de vihuela, le dirige dos composiciones. Es importante, en este contexto, el elogio de la música en endecasílabos blancos que aparece en los preliminares de la quinta parte de las Canciones y villanescas espirituales (Venecia, 1589) de Francisco 
Guerrero (véase la pág. 396: «Las almas perturbadas y dolores / puede aliviar la música: es deleite / con razón de los dioses y los hombres», etc.). Sin embargo, en raras ocasiones alcanza Mosquera de Figueroa momentos de elevación poética verdaderamente dignos de mención, como, por ejemplo, sucede en la «Epístola en respuesta de Medoro a Lucinda» (véanse las págs. 331-334), obra de encargo que contiene, empero, una hermosa descripción de la conversión de la voz poética en árbol después de su muerte (vv. 82 y siguientes).

La edición de Jorge León Gustà puede considerarse, en conclusión, necesaria: en primer lugar, porque ofrece por vez primera una edición íntegra y crítica de los versos de un poeta tan admitido en los círculos literarios de su tiempo como Cristóbal Mosquera de Figueroa; en segundo lugar, porque en su «Introducción» realiza algunas consideraciones sobre las posibles relaciones entre las respectivas obras poéticas de Fernando de Herrera y Cristóbal Mosquera de Figueroa, que se traducen, sin ir más lejos, en una acogida entusiasta del legado del elegíaco Propercio. 